\title{
STRATEGIES FOR SUSTAINABLE ECO-TOURISM DEVELOPMENT
}

\author{
Madhuri T. Sawant*
}

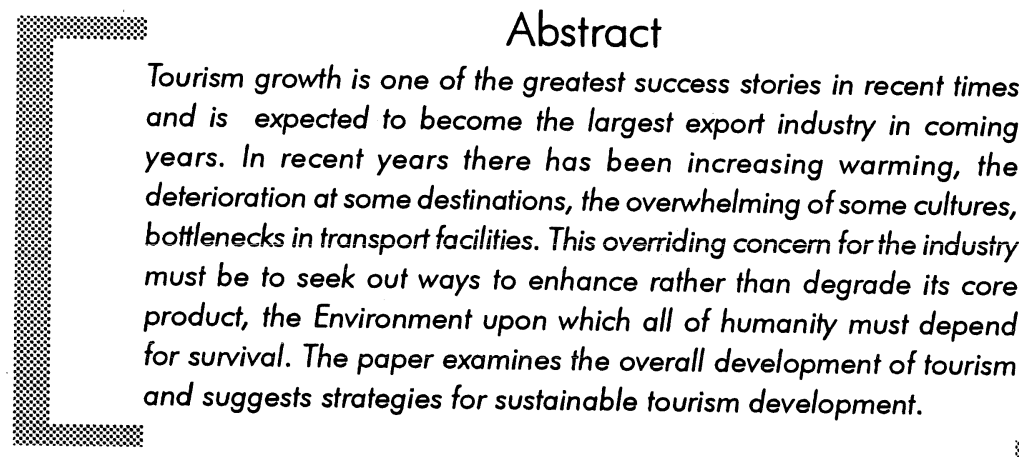

\section{Introduction}

Due to shrinking of natural areas world over and due to the fast declining number of faunal and floral species, the concern for conservation and preservation has increased. For centuries we have been clearing forest and burning coal, oil and gas, pouring carbon dioxide and other heat trapping gases into the atmosphere faster than plants and oceans can soak them up. This has created one of the \footnotetext{
* UGC JRF, Department of Tourism Administration, Dr. Babasaheb Ambedkar Marathwada University,
Aurangabad.
} 
greatest threats to our planet i.e. "Global Warming". It has become one of the most serious issue to maintain the balance of our ecosystem.

The environment is a tourism resource. It is the environment or rather the experience or enjoyment of it, which the tourism industry promotes and sells.

The close relationship between tourism and environment and the importance of environmental planning and sustainable tourism development planning are becoming increasingly recognized.

Education and better knowledge of nature and natural systems have made people realize their own role in conserving nature, hence new concepts like sustainable tourism, green tourism, eco-tourism etc. have therefore emerged in the field of travel and tourism which not only helps in environmental conservation but also in socio economic development of the area.

\section{Environmental Conservation}

It refers to the planned management of specific sites and places and natural resources in general and not necessarily categorical preservation which is used to make no change at the site, place or resources. Sometimes, it includes restoration to its original condition. Conservation implies that some use and controlled change can take place if the basic integrity of the site, place or resource is maintained.

Eco-tourism enhances appreciation about nature and natural areas that contributes to the conservation of environment and cultural monuments as well as the well being of the local people. It has become a busy word to describe the mutual interest of conservationists and tourism industry in promoting sustainable tourism. Eco-tourism thus helps in planning and conservation of nature with the help of strategic management.

\section{Eco-Tourism : A Tool for Conservation of the Environment}

The eco-tourism society defines eco-tourism as a purposeful travel to natural areas to understand the cultural and natural history of the environment, taking care not to alter the integrity of the ecosystem while producing economic 
opportunities that make the natural resources financially beneficial to local citizens. Eco-tourism planning in its full sense is proactive, responsive to community needs, perceiving planning and implementation.

It is about achieving a desired end eg, the objectives identified for the management of tourism resources. In the case of sustainable tourism planning and development, the "Strategy" is the use of appropriate visitor management, conservation of nature and planning practices to achieve the various objectives.

The strategy includes:

\section{Environmental Protection and Conservation}

The environmental damage is aggravated by frequency of visits. The huge influx of tourists have created problems in eco-tourism products such as caves, lakes, beaches, hill stations, national parks, bird sanctuaries and cultural monuments.

The flora and fauna have been damaged a lot, it is due to pollution, which is being associated with tourism, which relates to problems of inadequate sewage disposal, air, water and noise pollution. Deforestation and hazardous infrastructure development has created problems of ecological balance, which has worried conservationist and environmentalist. There is an urgent need for conservation and preservation of these eco-tourism products.

Tourism can be a major factor in reversing the trend and enabling the area to become a beautiful place to live in, to relieve the environmental pressures careful planning and management of most popular tourist areas is required.

\section{Study the Environmental Impacts}

The environmental impact assessment $(E I A)$ is the most widely used procedure to assess the impact of development on the physical as well as economical and social environment.

There are positive as well as negative impacts of tourism on the environment.

The positive impacts are;

1) Making the tourist ecologically aware.

2) Conservation measures have come up.

3) Initiatives are pouring in to minimize pollution. 
4) Maintenance of scenic beauty, historic sites, wildlife and monuments.

5) Research is done widely.

6) Environmental studies are being taken up.

Negative impacts are;

1) Air, water and noise pollution.

2) Waste disposal problems.

3) Ecological disruption.

Overuse of fragile environment by tourist leads to ecological damage wildlife is harmed on a large scale. Deforestation of ski-slopes may lead to erosions, landslides and avalanches. Uncontrolled photography and regular feeding to animals disturb animal behaviour pattern. Their habitats can be disrupted or reduced by excessive encroachment of tourism development at the sites. The coastal and mountain environment is particularly vulnerable to overuse and uncontrolled tourism are bound to deplete the endangered species.

The implementation of informal or scaled down, EIA procedures could benefit a community in number of ways.

1) Serving as a means of pre-qualifying projects it can be used as an assessment tool to and in identifying ecologically viable and sustainable eco-tourism projects,

2) Having environmental and cultural preservation as its goals. It can direct development to occur in ways, which are more energy efficient and culturally compatible through appropriate design.

3) Considering all of the relevant environmental, economic and social impact of the project it can promote balanced development through integrating environmental protection with eco-tourism development.

4) Encouraging wide participation in the process of evaluation and assessment it can be a proactive strategy of eco-tourism development which educates everyone involved including developers, business people, government officials and villagers; and

5) Requiring projections of resource uses and their consequences at the outset it encourages a long-term eco-tourism anticipatory planning approach by the government and developers so that costly changes in development plans can be avoided. 
In this way EIA could be a vehicle by which government provides assistance and service for responsible tourism, which would reduce environmental impacts leading to economic, socio cultural benefits and nature conservation.

\section{To Study Physical Design, Infrastructure development and carrying capacity}

It is important to determine the types and facilities available in the proposed destination and the future needs based on the EIA parameters.

1. Provide architecture, consistent with environmental philosophies and / or scientific purposes.

2. Local age-old practices for house building, soil conservation, waste management, development of potable water system should be considered.

3. Provide building forms and images in harmony with the natural environment, maintenance of ecosystem should take priority over view. Use low-tech design solutions wherever possible, energy intensive products or hazardous materials should be avoided.

4. Use naturally felled trees and avoid cutting significant trees to minimize disruption of natural features.

5. Trail system - It should respect travel pattern and habitats of wildlife

- Traditional and well-established trails must be preferred.

- Minimize trail-crossing points at rivers and streams.

- Provide trailhead signs to enhance appreciation of natural environment and to clearly establish rules of conduct.

6. Involvement of local inhabitants should be encouraged to provide input for the designer as well as a sense of ownership and acceptance by local residents.

7. Buildings should be spaced to allow wildlife travel pattern and forest growth.

8. Prominently pass an environmental code of conduct for visitors and staff.

9. Visitor centers must be necessary to provide proper information and education to visitors. 
Construction specifications should reflect environmental concern regarding use of wood products and other building material.

\section{Carrying Capacity}

Carrying capacity is the maximum number of people who can use a site without an unacceptable alteration in the physical environment, quality of experience gained by visitors and adverse impact on the society, economy and culture of tourism area.

There are three basic types of carrying capacities
1) Physical Carrying Capacity
2) Biological Carrying Capacity
3) Social / Cultural Carrying Capacity

Physical Carrying Capacity - It is the capacity of a natural area to hold a certain number of eco-tourists, residents, activities, and facilities. This concept is important since natural resources and infrastructure is limited or overused. Exceeding the Physical carrying capacity of an area can bring deterioration of natural resources. Standards can help the developing countries avoid over development or rapid development.

Biological Carrying Capacity - It describes the interaction of eco-tourism on plants and wildlife in the ecosystem. Government can assist in protecting biological resources by establishing national parks and wildlife preserves particularly in sensitive areas such as rainforest and mangroves.

Social / Cultural Carrying Capacity - It relates to the impact of visitors on the lifestyle of local residents. Proactive measures are needed to ensure positive interactions and to minimize social disruption. Educational materials should be provided by the government to instruct visitors on how to behave with respect to the local culture and customs.

\section{Use of Waste Management and Eco-technology Waste Management}

Disposal of wastes and management of waste is an uphill task for the government, their agencies and organizations. Waste management system is one of the most important aspects in this context. 
The concept is designed to reduce Consumption, increase the efficiency, eliminate toxic inputs maximize recycling and ensure that products are made to be safely reused, repaired or recycled back to nature or the market place.

The major benefits include

1) Less waste cost, re-cycling is more cost efficient than land filling.

2) Employment generation through waste reduction and recycling initiatives.

3) Income generation from resources / commodities otherwise destined for landfill, creating employment.

4) More environmental preservation and natural heritage conservation.

5) Reducing pollution through decreasing littering \& others.

It is necessary to separate different types of resource users by adopting zoning. This will help to separate different types of density of use allowing lower density in areas where more resource protection is desired.

\section{Ecotechnology}

It is a must to develop an appropriate technology, which reduces pollution, uses of local knowledge and materials and facilities recycling.

- There must be battery-operated vehicles within the protected areas to reduce air and noise pollution.

- It may be necessary to use renewable resources of energy such as solar power panels in remote areas.

- Tapping of wind energy / wave energy wherever appropriate.

- Limit the air conditioning.

- Natural ventilation techniques.

- Utilizing appropriate technologies for the treatment of organic wastes such as composting, septic tanks or biogas tanks etc.

- Recycle of wastewater for non-potable uses and treat tainted wasted before their return to natural environment.

New eco-friendly technologies must be introduced and monitor the effectiveness continuously. 


\section{Plan for Partnership with the Entities for Development and Training}

It is very necessary to plan for partnership with the following entities for ecotourism development.

1) Partnership with private sector, which can contribute for sustainable management.

2) Partnership among various government departments.

3) Partnership with non-governmental organizations especially in the field of developing strategies for local empowerment.

4) Partnership with academic institutions such as local universities, other local educational institutions etc in order to provide continuous training for those who involve in management of the eco-tourism resources.

5) Partnership with research institutions will help monitor the scientific parameters of sustainability developed for a particular eco-system.

6) The most important partnership is to be developed with the local communities since community based eco-tourism enterprises has to do a lot in environmental sustainability of the destination.

\section{Training}

Training and accreditation are two methods of establishing standards. A number of possible approaches to meet the requirements of training include;

- Develop training programs for tourism operators to enable them to communicate messages appropriately, be aware of the means to minimize adverse impacts of tourism, and provide opportunities for active involvement in environmental protection and management,

- Identify and address training needs for eco-tourism operators, guides and natural area managers,

- Raise awareness of the value of and the need for interpretation,

- Provide raining for natural area managers jointly with tourism operators to promote a better understanding of each parties interests and concerns,

- Include skills in communication in the training of operators and natural area managers, 
- Develop codes of Practice for eco-tourism operators, guides and tourists,

- Require that appropriate training be a pre requisite for accreditation, and

- Use incentives to encourage training.

\section{Economic Implication}

An ethical perspective on eco-tourism would require that the concept not only should ensure environmental sustainability but also should provide for the sustenance and contained protection of the socio cultural identity of the locality and economic benefits.

The major economic benefit of eco-tourism is its potential to generate revenue as well as implements a service sector activity that can create stimulations for the economic development of peripheral and adjacent remote areas as well. Economically depressed areas are even better saved by the activity.

The multiplier effect where the benefits of direct income and employment which are internally circulated to create dated income opportunities are;

1) The start up and operational expenses, start up expenses include the site acquisition and provision of infrastructure facilities and other services. Operational expenses include the maintenance, labor costs and the marketing expenses.

2) Employment opportunities as guides.

3) Establishment of sales units for handicrafts, souvenirs etc.

4) Local food

5) Sustainable exploitation of biodiversity for medical purposes, harvesting of seeds and other Agricultural products.

There must be organized efforts to create awareness among the locals and impart them training specially the local youth for various employment opportunities.

The natural environment and their richness in biodiversity are rapidly emerging as lucrative tourism destination, its potential to afford a mars of activity and to generate revenue through these activities would generally suffice it self as justification for the retention of the destinations in their natural state and help in the conservational efforts. 


\section{Regional Development}

The major benefit to plan eco-tourism development provides benefits for local communities and their natural and cultural environment.

The over all development depends on the three main principles of sustainable development.

1) Ecological sustainability ensures that development is compatible with the maintenance of essential ecological process, biological diversity and biological resources.

2) Social and cultural sustainability ensure that development increases peoples control over their lives, is compatible with the culture and values of people affected by it.

3) Economic sustainability ensures that development is economically efficient and that resources are managed so that they can support future generations.

Taking into considerations all these factors, a sustainable tourism approach can be developed which can help not only Regional Development but also help in conservation of Nature and overall development of the area.

\section{References}

1. Satish Chandra Nigam, (2006) Eco-tourism and Sustainable Development, New Delhi.

2. Harish Bhatt \& B. S. Badan, (2006) Eco-tourism, New Delhi.

3. M. Sarngadharan \& G. Raju, (2005) Tourism \& Sustainable Economic Development, New Delhi.

4. IITTM, (1997) Journal of Travel and Tourism, Gwalior.

5. IITTM, (1996) Report of Sustainable Tourism Development, Gwalior. 